\title{
IDENTIDAD POÉTICA DEL UNIVERSO FEMENINO EN LA CULTURA ESTÉTICA TOCANTINA EN MARABÁ
}

Alexandre Silva dos Santos Filho 


\section{POETIC IDENTITY OF THE FEMALE UNIVERSE IN THE AESTHETIC CULTURE TOCANTINS IN MARABA}

\begin{abstract}
One of the symbolic worlds of the feminine is the poetic production through aesthetic elaborations, whose specific theme deals with the cultural identity of women in the Amazon. This research aims at examining the occurrence ofanaestheticcultureofdifference, produced by representative groups of women, who process symbolic goods through the work of the plastic arts and who mobilize aesthetic diversity through confrontation with difference. Therefore, it is expected to reflect on the poetic immanence of the Amazonian woman in southeastern, culturally marginalized, subaltern to urban conditions, influencing the frontier of the object to be something more in the feminine life, under the sign of touchiness.
\end{abstract}

Key words: Aesthetic Culture, Cultural Difference, Feminine Cultural Identity, Amazonian Woman Poetics.

AUTOR

Alexandre Silva dos Santos Filho

Doctor en Educación Universidad Federal de Goiás.

Docente Universidade Federal do Sul e Sudeste do Pará - UNIFESSPA.

Correo electrónico: alixandresantos@gmail.com
RESUMEN

Uno de los mundos simbólicos de lo femenino es la producción poética a través de las elaboraciones estéticas, cuyo tema específico trata de la identidad cultural de la mujer en la Amazonia. Esta investigación tiene como objetivo examinar la ocurrencia de una cultura estética de la diferencia, producida por grupos representativos de mujeres que procesan bienes simbólicos por medio del trabajo de las artes plásticas y que movilizan la diversidad estética por el enfrentamiento con la diferencia. Por lo tanto, se espera reflexionar sobre la inmanencia poética de la mujer amazónica en el sureste paraense (culturalmente marginada, subalterna a las condiciones urbanas) que influye la frontera del objeto a ser algo más en la vida femenina, bajo el signo de una tocantinidad.

Palabras clave: Cultura Estética, Diferencia Cultural, Identidad Cultural Femenina, Poética de la Mujer Amazónica.
Recibido: 15/09/2017

Aprobado: 15/11/2017 


\section{INTRODUCCION}

La producción artística femenina en la cultura estética tocantina ${ }^{1}$ acata aspectos referentes a la individualidad de cada ser, se remite a la sensibilidad que se forma a partir del juicio de gusto de las mujeres que hacen arte en el territorio de la Amazonia marabaense. Todo indica que existe en la dinámica sociocultural un conjunto de factores sensibles, mediante el sistema del arte, que se incorporan en la identidad poética de esas artistas: el lugar, el ambiente de trabajo en la creación artística y las condiciones materiales que el experimento es capaz de proporcionarles.

En lo que se refiere a la experiencia artística, se observa que ésta se inserta en un problema característico de la localidad y el medio ambiente donde las mujeres artistas habitan. Son factores que influyen en la percepción del lugar, que involucran una atmósfera visual e interactúan con las vidas de las mujeres que habitan la ciudad bajo el signo de la inmanente tocantinidad. Implica, de otro modo, presencia y marca de un ethos amazónico de la feminidad, visible en los modos de producción cultural, existente en un tiempo que no se subordina al tiempo que se instala en las sociedades amazónicas por el interés del capital.

La producción de obras visuales femeninas con base en la cultura estética tocantina es aplicación ambivalente de la forma viva -forma que vive en la sensibilidad desplazada por la vida que traduce muchas otras identidades características de la belleza-, es vida que se transforma en cosas fabricadas por las manos de mujeres que se proponen moverse con la poética y el mito. A partir de ese principio, se toma una acepción shilleriana para decir que el precepto está en el impulso de realización de las tareas, consumando objetos por la necesidad de la cristalización de la percepción femenina o por la toma de conciencia perceptiva del mundo amazónico. Por otra parte, gracias al trabajo de las mujeres artistas se moviliza un saber y se ordena un modo de hacerse mundos sensibles, conduciéndolos por la forma viva en el imaginario amazónico como fuerza activa. Es la experiencia como realidad material e histórica femenina.

Tal concepción traduce el trabajo artístico como producto histórico del proceso de creación, a lo largo de la formación de las narrativas en la Amazonia. Sobre todo, este estudio valida un conjunto formado por cinco artistas de la comunidad marabaense como ejemplar del discurso visual, con una producción poética emergente en una temporalidad, cuyo espíritu se representa por el lugar que establece la presencia de una estética de la diferencia, producida por la minoría trabajadora con el arte, actuantes en la comunidad tocantina.

Por medio de pinturas, construcciones, fotografías e instalaciones se visibiliza a estas productoras artísticas: Ezita Machado, Teresa Bandeira, Creuza Salame, Lara Borges y Líris Pimentel. Se percibe en medio de la estética de las amazoninas un impulso capaz de accionar imágenes vivas en la sensibilidad de la mirada. En esa perspectiva, las diferencias se captan por comunicaciones y territorialidades visuales, presentes en los intersticios de los sistemas poéticos inmanentes, en la frontera del objeto, cuando el impulso lúdico -la forma viva- es condición fundante de éste en la estética tocantina.

${ }^{1}$ Designación predicativa al río Tocantins, ya que su interfaz con la ciudad de Marabá crea una sintonía referente al río como signo indeleble de una territorialidad. 
El entendimiento en el arte como organismos vivientes (gracias a cuyo proceso de elaboración poética se hacen posibles, a partir de la materialidad que se objetiva) indica una necesidad formal, viva y que cuya vida sea en rigor la propia forma. Sólo así, cuando la forma en todas sus relaciones se presente al pensamiento como elaboración de un trabajo artístico, que se cristaliza en "obra de arte" es que estará lista para redirigirse y seguir un camino, simplemente por un paso en dirección a los imperativos sensibles, a fin de negociar el conocimiento, el consumo y el espectáculo.

Lo que se pretende, de otro modo, es reflexionar sobre las marcas que dan estabilidad al proceso de creación, pero que nunca son capaces de cerrarlo en un sistema estético sin permitirle transitar por un campo ampliado de las resignaciones estéticas femeninas. Conviene también observar que la negociación de una identidad femenina en la creación artística local produce lastre en la historia intersticial y que tiene propósitos definidos en actos de memorias de la comunidad.

No basta sólo un estado de espíritu para vivir la amazonidad. Es indispensable que exista un elemento materializado, manipulable y añadido a la creación artística local en sintonía con la ecología en pro de la supervivencia, aunque sea precaria su existencia. El resultado de la obra de esos artistas es como un organismo vivo que muta mediante la interdependencia e intervención de la acción femenina; razón por la cual, se puede decir que se construye de modo simbólico y no está simplemente inscrito en la naturaleza de los valores de intercambios y de uso, sino bajo la marcante presencia de la identidad de la mujer en la región amazónica.

La inquietud sobre la experiencia artística se refiere a la libertad intelectual de esas mujeres, ya que en términos de la demografía artística femenina está restringida a una pequeña comuna de fuerza humana individualizada y que aún no ha entregado el trabajo creativo a una estructura de dominación de fuerzas vitales. La premisa en esa reflexión parte de lo siguiente: la necesidad de una afirmación femenina objetivada produce el embate con la identidad poética en la cultura estética tocantina.

Se sostiene que la producción artística femenina es herencia guardada en los intersticios de la poética tocantina, pero que aparece en el tiempo de los actos creadores artísticos, fuera de la temporalidad contingente. Con la teorética schilleriana (2002) se podrá decir que la humanidad es posible, siempre que sea vista la temporalidad de los marginados, de los insurgentes y excluidos. En ese caso, el acto creador de las mujeres tocantinas es eso: trabajo inconmensurablemente cotidiano. Por otra parte, es un encuentro con la propia naturaleza en la cultura estética que aparentemente se aísla, pero sobrevive y teje su resistencia.

Decimos entonces que la forma viva influye en el modo de vida de esos artistas, se instituye a través del trabajo objetivo con los elementos de la territorialidad amazónica y por eso esas mujeres experimentan realizar un trabajo que exprese su naturaleza femenina. Así, pueden manipular elementos sígnicos, se apoderan de narrativas orales y visuales para representar actos de origen físico o intelectual.

Es, por lo tanto, en esa posición amazónica que se pone en escena, en la que se auto identifica, afiliada a la forma estética, en el dominio de lo fantástico, de la naturaleza exuberante, de la visualidad y sonoridad envolvente, el significado de la palabra, de lo económico, de lo político y de la raza como fondo de una temporalidad que se instituye y al mismo tiempo, subyuga lo cotidiano en la 
modernidad amazónica, marcada por el acto de insubordinación a los grandes proyectos en el sur y sureste paraense.

\section{LA IDENTIDAD POETICA FEMENINA COMO ACTO DE REMEMORACION EN LA ESTÉTICA TOCANTINA}

El acto de la rememoración trae a la superficie la memoria que constituye el sujeto en su cotidiano intersticial, su historia ordinaria; transforma el presente de los acontecimientos, históricamente oculto por pertenecer a los grupos minoritarios. Busca la comprensión de lo que componen la estructura narrativa liminar del imaginario amazónico femenino, centrado en el hacer y en el mito poético como fuente de la memoria visual y estética.

La caracterización de la estética tocantina por este medio es, pues, particularizar una idea estética inseparable de sus elementos reflexivos y críticos, ya que no existe una calidad estética fragmentada que sustenta tal suposición. Además, es posible extender el acto reflexivo para el proceso de interpretación de la cultura estética en los espacios liminares del orden de las sociedades en la Amazonia.

Para el entendimiento de la estética tocantina se tiene en cuenta la ley general de la teorética que la fundamenta. Se imprime una base para pensar el principio de la estética, se tiene en cuenta la diferencia cultural, cuya forma viva se confronta con el saber y el hacer de las prácticas instituidas hegemónicamente, consistente en la contradicción, ya que se debe negociar en vez de negar. A través de este enfoque, se dibuja la cultura amazónica en una atmósfera que enlaza el ser humanorelativo a la naturaleza, reflexionando sobre el significado de las mujeres artistas impregnadas con los signos de la realidad cultural subyacente.
Es cierto que todo eso incita a pensar el mundo amazónico resultante de una cultura que tiene relación con la estética. Sobre todo si la impregnación es dada por sensaciones físicas, pero no se limita a esa condición, ya que el significado es dialógico y ambivalente, calcado en el sentimiento estético de superar las densas paredes de las sensaciones y alcanzar lo estético a partir de la fuerza que impulsa la experimentación, la variedad y las posibilidades creadoras. Para ello, las sensaciones producidas por el objeto de la naturaleza tocantina definen la forma estética como representación en el ser humano. De ahí la creación artística, en esa condición, es resultado de un repertorio acumulado por las mujeres artistas en el mundo amazónico.

A través de eso, la relación mujer/naturaleza se inserta en un valor estético e histórico, cuyas reglas son vislumbradas con la experiencia sensible, alcanzadas por la proximidad de la mujer amazónica en función de la naturaleza; capaz de promover la interfaz de las acciones con las personas nativas y otras en constante tránsito por la región Amazónica. En virtud de ello, la dimensión poética sirve para definir una estética tocantina acuñada en la siguiente formulación: el arte busca en lo humano aquello que perdió de la naturaleza, pues lo que restó en ella es libre creación humana. Este sentido de preservación que se observa es una preocupación fundamental para decir que es indispensable construir una cultura estética orientada hacia y con los designios de una humanidad sensible. De ahí se hace la visión local, no fragmentada, sobre la base de un método con el que soporta el desdoblamiento en la dimensión reflexiva.

Aún más por qué en esa dimensión reflexiva no se discute el aura de algún significado perenne por la cultura homogénea en esa tocantinidad. Es importante resaltar que no se puede considerar la cultura estética 
amazónica en el mismo grupo que otras en el planeta, a pesar de que la teoría estética tiene el sentido universal de la base reflexiva en esa cuestión. Se justifica, además, que la particularidad estética en cuestión es la de la diversidad cultural estética en el entre-lugar, cuya característica es de la negociación de los significados, fronteriza, descentralizada y ambivalente. Es una cultura estética hibrida percibida bajo una diversidad de señales sensibles en la materialidad mediante el contexto de la amazonidad, apareciendo ésta bajo la forma de las raíces de la ancestralidad del pueblo de la selva amazónica. Y sus desdoblamientos de identidad son reescritos a partir del conjunto de valores sensibles, formales y lúdicos.

Si es por intermedio de la amazonidad tocantina que se revelan los sentimientos de las mujeres artistas, se debe entonces considerar otras ocurrencias en ese contexto de los cambios significativos; se destaca su forma de participación en los movimientos sociales, en los conflictos de tierras, en la transformación del bosque (explotación de la superficie y del subsuelo), en las invasiones subyacentes por factores económicos y mediáticos.

En la poética del imaginario femenino, hay voces estetizantes que se dirigen a la cultura amazónica. En este conjunto de valores han surgido históricamente en la región, voces con poder de cambiar o de hacerse oír para demandar cambios con fuerza en la política, estética, economía y acción en la sociedad, ejemplificada por Loureiro (1999) al subrayar la dimensión política del arte en el Estado de Pará.

La cultura estética tocantina femenina puede ser entonces dicha así: traduce de forma actualizada, a partir de preceptos, el papel de mujer estetizada por el discurso de la localidad, antropofágica e histórica. Por otra parte, es del orden del territorio de la producción poética de la minoría, frontera intersubjetiva que marginaliza la experiencia del hacer, resultante de las diferencias culturales cotidianas. No es difícil entenderlo ya que en diferentes situaciones se puede encontrar la expresión creativa de la mujer tocantina, tensada con los valores de una estatización de la masa, mediante una simultaneidad de interacciones con base en los fenómenos de la cultura y comunicación de masa.

En la amazonidad hay un papel que se destaca en ese contexto. Es la del mestizaje y / o caboclo (a) en la convivencia con la cultura estética en su lugar de origen. Esta situación desdobla un aspecto especial y que va introduciendo elementos de otras formas culturales, además de moldear significados que se van desarrollando por el consumo de elementos estéticos ajenos a la producción local. Se alimenta entonces de diferentes fuentes sensibles, de otras culturas y contenidos (comunicacionales o no) para entonces crear una estética cultural en lo plural.

Opera, sin embargo, un conjunto de factores composicionales y visuales, organizacionales y estructurales -la racionalidad estética-, perteneciente al conjunto de relaciones objetivas que no sólo expresa la actualidad de la cultura estética sino que también se impone, se crea una en el imaginario amazónico mediada por temas de todos los ámbitos del sistema ideológico. Esta estética tiene privilegios y es exigente pues todo indica que es una estética en la acción humana de la cultura amazónica pero que también necesita elementos para una educación de los sentidos y de la sensibilidad.

Es bueno no olvidar que las culturas se mezclan, producen efectos significativos, siguen un proceso intercultural. Para Bhaba (2010), la producción de 
cultura a partir de minorías destituidas es acuñada como cultura local. Esto tiene fuerza para pensar que la cuestión se apoya en la idea de una cultura interestatal amazónica, con fundamentos teóricos prevalecientes, comprendiendo su funcionamiento en relación con la autonomía, sin excluir las influencias extrañas, sino antropofágicamente definidora en sus extensiones.

\section{CULTURA ESTETICA HIBRIDA EN EL UNIVERSO FEMENINO}

Las cinco mujeres artistas identificadas por este estudio cristalizan sus pensamientos y performances en materialidades propias. Se mueven con el tiempo desterritorializado, ya que es un tiempo para la realización del trabajo artístico vinculado a la forma y al contenido de la obra y no al tiempo de trabajo para la producción de mercancía. Estas mujeres tejen una poética fuera del alcance de la significación hegemónica en la sociedad amazónica, pues están en contra de la actividad forzada y que cultivan la satisfacción del acto creador y libre. En las líneas de (d) estructuración artística, estética e intercultural cumplen un papel sistémico y rastrean la forma viva en la producción emergente de la feminidad amazónica, revelándose en un discurso visual no dominante, pero desafiante de leer códigos no hegemónicos. En ese sentido, se toma como significado del universo femenino de la cultura estética tocantina en Marabá, a las artistas: Creuza Salame, Ezita Machado, Líris Pimental, Lara Borges y Tereza Bandeira.

Mediante la obra de Creuza Salame hay que encarar dos desafíos y una nueva experiencia de vida. Desafíos que traen la obra al despojo de un mundo cristalizado en una poética de carácter no hegemónico. Puesto que todo lo que está dicho y construido por la agencia de la globalización de los valores instituidos, por intermedio de una cultura de imposición, entra en contradicción con la razón y sensibilidad estética de Salame.

Su poética es ambivalente e inconmensurable, pero tiene condiciones necesarias para otorgar la expresión contemporánea de la estética de la diferencia. La artista rompe con el ordinario cotidiano y al mismo tiempo busca en él su materialidad: compone piezas impregnándolas de amor y odio, bello y feo, frágil y resistente, material y espiritual. A cada instante tira de la alfombra de la razón y hace creer que hay que dialogar con la extrañeza.

Lo que es extraño desliza del significado impuesto, ser y no ser es más lo que se puede ver: es perturbador en el dominio del contenido significante. Por otro lado, si la privación del entendimiento sobre la obra está corroída es porque ella exige otra referencia para la enunciación estética, una reelaboración de la mirada acostumbrada a lo traducible y no con un contenido dado que se vuelve extraño a la dinámica de la fuerza viva. Esta última no está en la obra gratuitamente, es parte del sentimiento de no querer "todo listo" y que para eso hay que pensar. Es un primer desafío.

El segundo desafío es el de encontrar en los recortes de la materialidad -entre el diseño y el objet trouvéuna experiencia estética vivificante como rastro interdisciplinario que permita contextualizar la creación de la artista. Se suscita entonces reflexiones provocativas para comprender el significado de la estética de la acumulación. Se dice esto porque lo que se revela a los sentimientos cuando se mira en la superficie de la obra, es fruto de una estética tocantina vivida en el territorio amazónico por la mujer que expresa y desafía un modo de producción de una minoría productora de arte femenino. Enfrenta la condición de los grados estéticos variados en esa oportuna situación, dada por la visualidad del Ensamblaje. 
No es necesario conocer la trayectoria creadora de esa musa de los Recortes Cerámicos para entender una única cosa que tiene sentido en su acto creador: la experiencia estética del caos.

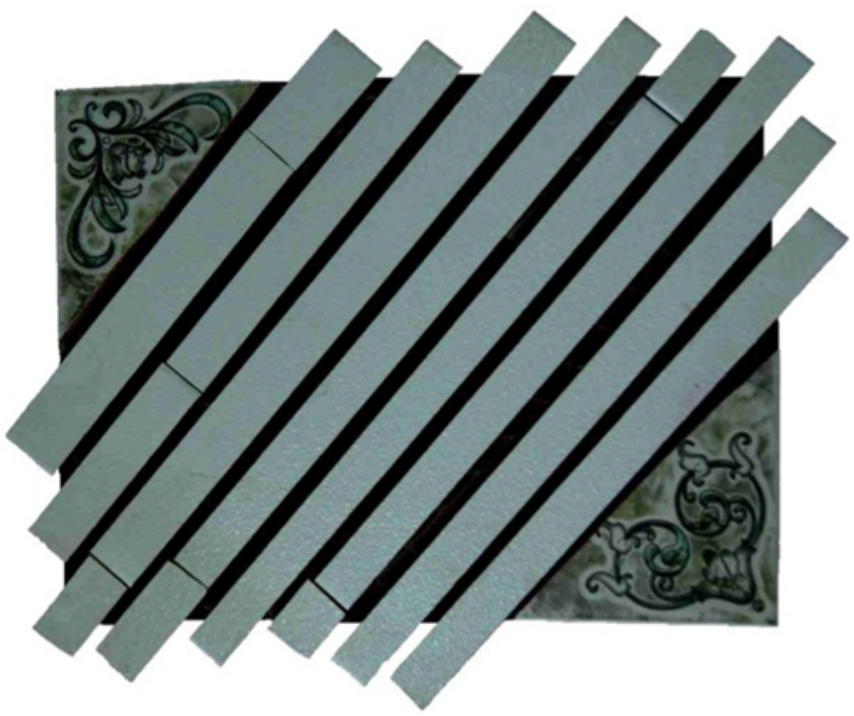

Obra en Cerámica de Creuza Salame, 2012 Hecha con restos de lazos encontrados en lugares de construcciones

La imaginación artística da cuenta de emprender en el caos la tarea de cambio, cuya situación de la percepción humana, acerca del mundo, está inserta en el desorden que opera la inconmensurabilidad. Ehrenzzweig (1969) define la idea del orden oculto del caos de la siguiente manera: “[...] cualquier trabajo verdaderamente creador necesita que se pongan a un lado algunas maneras de encarar el pensamiento racional y la creación de imágenes claramente cristalizadas. En ese caso, la creatividad significa autodestrucción" (p. 15). Es decir, la cara oculta de la narrativa visual es la tragedia de la creación: la no comprensión de la obra por el público. Creuza Salame es una creadora de imágenes, experimenta y se revela en una poemagógica (simboliza la creatividad del ego de quien hace algo con la pretensión de decir cosas al mundo); por cierto, ella dice cosas que para los demás no tienen finalidad, usa objetos descartados, encontrados por casualidad, visible sólo por su ojo sensible, mágico. Explora el intersticio del imaginario, transformando el proceso creador en interacción simbólica.

El hibridismo cultural de los Ensamblajes de Creuza Salame es acuñado en la estética tocantina. Su elaboración es temporal, a fin de poder negociar los significados de su trabajo libre, ya que las estructuras están estructuradas y tienen el poder de ser estructurantes. En esa vía, en su interpelación pedagógica, la intención es desterritorializar para entonces erigir un arte contemporáneo extraordinario.

Ezita Machado es pintora que transita por la contextura interdisciplinaria, trae en su discurso estético visual la conexión con la figura femenina, signo emergente de la cultura amazónica como un elemento ambivalente e inconmensurable existente en la narrativa de lo diferente, cuya interactividad circula dentro del tiempo corto del discurso de la minoría. Capta así la estética cotidiana en su imaginario, promoviendo una narrativa disyuntiva con el tenor de contar historia, de lo que existe en las comunidades del bosque.

En esa perplejidad, vivir, pintar y resistir al tiempo vacío y homogéneo -el tiempo de la modernidad cultural-, se convierte a otro tiempo, al tiempo del anonimato que trae la presencia de su obra en el entre-lugar. Bhabha (2010) define este aspecto destituyendo el tiempo de la serialidad progresiva o lineal del recorrido de la construcción poética del presente que sucede: “[...] suplanta la noción profética de simultaneidad -a-lo-largo-del-tiempo" (p. 222). Es decir, la narración en la obra de Ezita está constituida por el signo que sale 
de la alienación del lugar imaginado para ganar una dimensión en el tiempo a partir de lo inconmensurable.

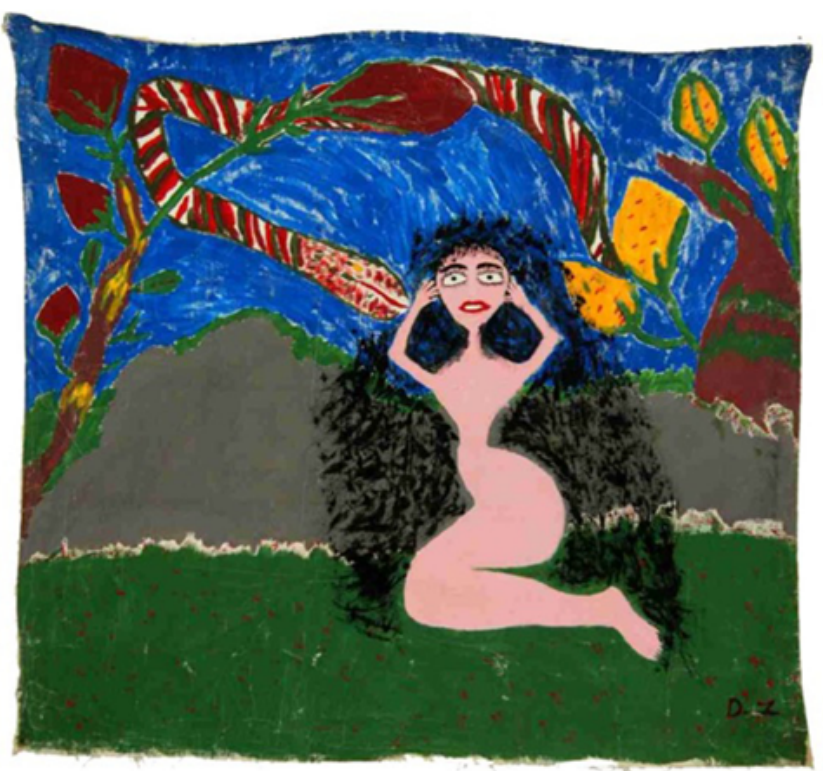

Ezita Machado. Eva. Pintura óleo sobre lienzo. 100×100 cm. Los signos de la narrativa visual performatizan la construcción del discurso poético.

La extraña temporalidad de Ezita niega su vínculo con la estetización hegemónica - síntoma de sociedad mediática - y la vincula a la memoria de la mujer que resiste como pintora en el centro de la región del carajá-tocantins. La imagen simbólica femenina sale de su imaginario como una pedagogía de vida, de voluntad de contar historia, pero en el fondo significa supervivencia y resistencia - síntoma de sociedad gregaria-.

Liris Pimentel es una fotografía de los intersticios, construye una mirada práctica y difunde la esencialidad de la imagen como algo a compartir con los demás. En el caso de las personas, ella crea un enigma de la imagen como una práctica de saber que la materialidad puede darle como soporte a su imaginario poético.

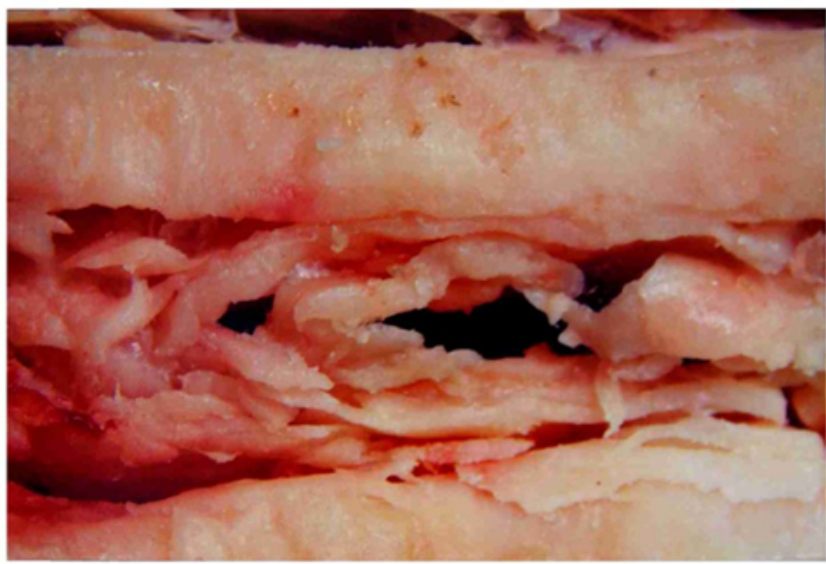

Fotografía de Liris, 2013

Obra realizada a partir de las entrañas de peces de la región

El conocimiento de Líris depende de los descubrimientos que hace con la imagen fotográfica, pues lo que ve pasa a ser sustancia fundamental para renovar su repertorio sobre lo que pretende simbolizar o transparentar con su discurso fotográfico de las entrañas (extrañas) dejadas como extrañamiento para la mirada estructurada en el tiempo homogéneo.

A partir de la inestabilidad del significado de las imágenes, provenientes de las entrañas de las frutas, raíces y peces se propone crear una percepción emergente de los intersticios. Con ello identifica zonas de inestabilidad ocultas en la imagen con el intento de intensificar el diálogo con lo menos visto, el nunca percibido y el no identificado. Crea así su rendimiento visual disyuntivo y ambivalente.

Lara Borges experimenta tres momentos de creación artística con base en la producción poética con el 
lápiz labial. Explora el mundo femenino no tradicional y encuentra a las prostitutas. Estas mujeres de la vida pasan a ser el blanco simbólico de su creación artística pues establece diálogo con sus cuerpos dominados, percibiendo una frontera díaspórica que se define entre el espacio social y la disyunción temporal. El cuerpo es deseo, voluntad y sensualidad, transpira el tiempo pedagógico destituido de su performatividad. Lara, entonces, quita de ellos registros, hace grabados, quita copia de sus partes indelebles y les atribuye cuerpos matrices de los grabados hechos con lápices de labios.

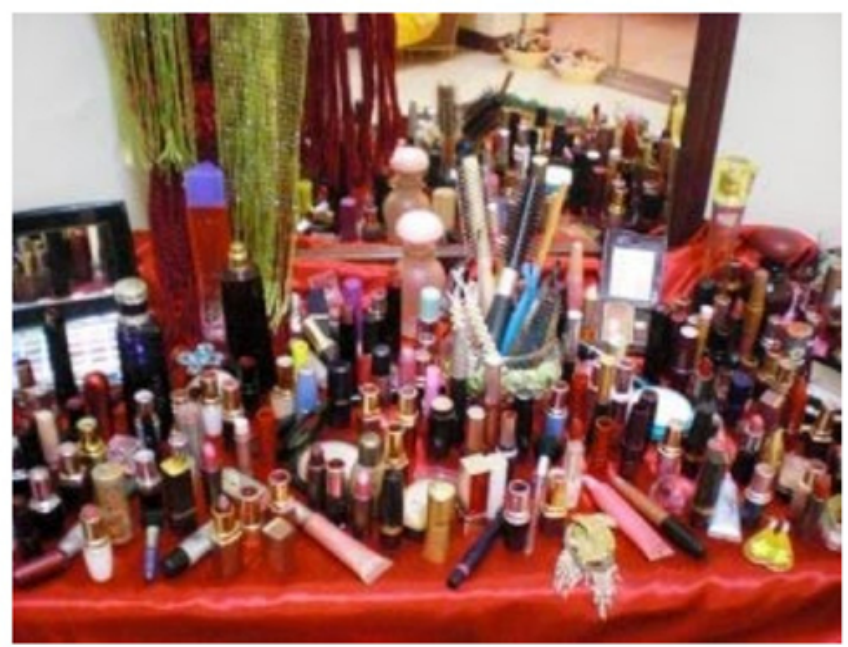

Peine de Lara Borges. Los lápices de labios forman parte de su rendimiento visual.

La narrativa corporal no termina el lugar de la creación poética de la artista, en realidad, amplía su significado, pues la forma viva está en la forma agonística femenina. Efecto este capaz de politizar y desmassificar la diferencia en la estética tocantina, puesto que el enunciado es disyuntivo en su elaboración poética, sea a través de la peinadora o del signo lápiz labial, tiene un lugar subversivo y de transgresión. El performático se pierde en la presencia del signo de la prisión que articula corrientes, llaves y candados, contraponiéndose al lápiz labial, lápiz de ojo, en el rímel, en la sombra y otros pertrechos que sirven para anular la identidad pedagógica del cuerpo marginado, pero que también interfiere en la cultura cotidiana del placer y la nulidad del otro, en el movimiento liminar del discurso de la minoría emergente.

Teresa Bandeira es un artista que construye su narrativa visual con base en dos importantes temporalidades: el lenguaje escrito y lo visual. Los signos que se inscriben en su poética, circulan dentro del significado que da a los fonemas un cierto aire jocoso y al mismo tiempo profético de la que deriva una significación cultural.

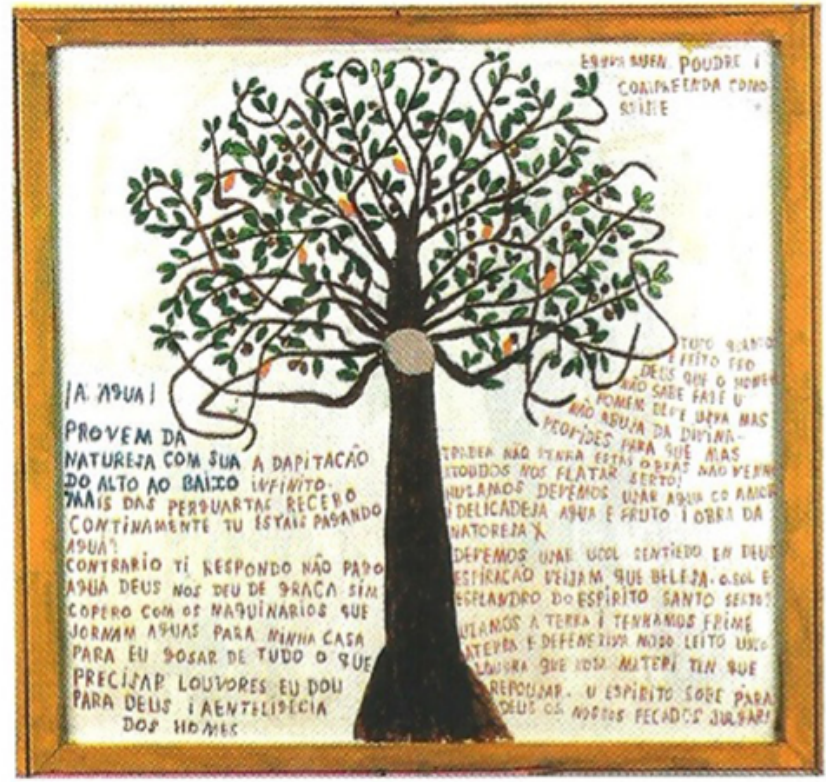

Pintura de Teresa Bandera, sin título, 2008

Lengua escrita y signo visual compone el imaginario social en la poética de la artista. Obra del catálogo de la 27ạ edición del Arte Pará (Maiorana, 2008) 
La artista rompe con la noción de tiempo homogéneo y vacío, se instala en el tiempo y desde allí discursa su presente como una forma de proporcionar vida a sus organismos visuales en un tiempo desterritorializado. Porque su enunciación narrativa es un memorial obsesivo de la causa amputada socialmente y que desprende ahora a través de la forma viva, en el vacío de la temporalidad histórica, su versión, su intencionalidad de [in] constituir la verdad violada de los seres humanos vivientes en su territorialidad.

"Absorbida por el silencio del interior de su casa-taller, Teresa barre el polvo cotidiano entre la forma de la letra y el fantasma del verbo impregnado sobre las paredes" describe Antônio Botelho (Mayorana, 2008). Por otra parte, es para decir que en su tiempo performático, entre paredes recubiertas de palabras sin órdenes conspira y / o insurge contra la poética del tiempo pedagógico en la historia. Teresa sale del lugar común, amedrentando la indeterminación, construyendo sentido con su discurso híbrido, en la frontera de lo accidental, del azar y del conflicto.

\section{CONSIDERACIONES FINALES}

Mirar, oír, ver, oler y tantear son aplicaciones sensoriales del cuerpo que resultan en retirar de la realidad externa elementos para nutrir posibles pensamientos. Son aspectos de una diferencia que emergen a fin de contextualizar y conocer el mundo para entonces explicarlo, decir lo que significa y tomar conciencia de él mismo, en sí para sí. Sobre todo, si todo esto son modos de representarlo en la condición manifiesta de su apariencia, articulando el saber que en la humanidad pretende acumulativamente exponer a su sensibilidad y entendimiento.

En la analítica de la diferencia el término estético cultural invade y transforma el escenario de la representación con base en la sensorialidad. No es suficiente la condición de la pasividad para imprimir significados, es indispensable que se tenga en cuenta el lugar de donde se crean las formulaciones simbólicas: sus efectos o determinaciones se interiorizan y hacen que el destino de la comunidad sea conturbado.

Si esas interiorizaciones son determinantes, al mismo tiempo se representan a sí mismo. Entonces, hay momentos en que el sujeto responde a la articulación sígnica en favor de su insistencia perturbadora en el discurso sociopolítico e intercultural de una estética en la creación artística. El significado de esto es la rearticulación sumada al “... conocimiento desde la perspectiva de la posición de significación de la minoría, que resiste a la totalización - la repetición que no retornará como el mismo..." (Bhabha, 2010, p. 228). Esto es intrigante, pues poder y saber resultan del desplazamiento dinámico de las prácticas artísticas de esas mujeres hechas en esa amazonidad, una vez que ellas producen otros espacios de significación subalterna.

En esa perspectiva, se observa que la producción poética de Ezita Machado, Tereza Bandeira, Creuza Salame, Lara Borges y Liris Pimentel representan no la contemplación, sino la afirmación constitutiva de un locus otro que sugiere el objeto de la creación estética ambivalente. Es el modo más significativo que la forma viva tiene para pasar por la poética de esas mujeres; no causa impresiones, sino choque repentino de significación o interrumpe la lógica formal y reescribe una racionalidad estética con base en contestación, conocimiento del mundo cotidiano, oposición a las formas de sentidos y estrategias para la construcción de identificación. Tales designaciones de las diferencias estéticas culturales se comprometen en la resistencia 
de una continua pertenencia a una traducción cultural cerrada y completa.

La producción poética de las artistas sacude el significado y el valor constitutivo causado por el proceso intercultural, puesto que sus obras ponen en perplejidad al espectador. Mediante lo que se ve, se percibe que la existencia de la obra en sí -en el ser otro- caracteriza la experiencia de un espacio liminar, cuya frontera del discurso visual es la confrontación de identidades. Moralmente, eso aproxima y aleja la forma viva de la comprensión en el fenómeno como estructura extraña, pues "... nos enfrentamos al desafío de leer, en el presente de la performance cultural específica, los rastros de todos aquellos diversos discursos disciplinadores e instituciones de saber que constituyen la condición y el contexto de la cultura" (Bhabha, 2010, p. 229). Ahora bien, simplemente del lado del espectador temporizado por la pedagogía de la historia en el sistema del arte, Ezita, Teresa, Creuza, Lara y Liris no hacen Arte.

La representación necesaria que se entrega al sujeto que busca comunicarse con la materia del múltiplo es la materia representada en la recepción estética, eso hace conexión interdisciplinaria de la forma viva, en el momento fronterizo, del acto de interpretar las obras de los artistas. Esta fuerza de unión invade al receptor del discurso visual que se abre a la sensibilidad perturbadora por el dominio del contenido significante de las imágenes.

\section{REFERENCIAS}

Bhabha, H. (2010). O Local da Cultura. Trad. Myriam Ávila, Eliana Lourenço de Lima Reis, Gláucia Renate Gonçalves. Belo Horizonte: Editora UFMG.
Ehrenzzweig A. (1969). Treatise on the Conflict. St. Paul: West publishing Co.

Loureiro, J.J.P. (1999). "Arte e Desenvolvimento (Teoria e Prática)". Caderno IAP. v.2. Belém (Pa): Instituto da Arte do Pará.

Maiorana, R.; et al., (Org.). (2008). Arte Pará. 27ạ. Ed. Belém: Fundação Romulo Maiorana.

Schiller, F. (2002). A Educação Estética do Homem: numa série de cartas. Trad. Roberto Schwarz e Márcio Suzuki. São Paulo: Iluminurias.
Citar este artículo como: Silva dos Santos Filho, A. (2017). "Identidad poética del universo femenino en la cultura estética Tocantina en Marabá". En: Revista La Tercera Orilla (19). Bucaramanga: Universidad Autónoma de Bucaramanga. 